\title{
Modelling of thermal effects in a slim tin fixed-point cell
}

\author{
Sergio A. Carvajal ${ }^{1, *}$, J. Herney Ramírez ${ }^{2}$, Andrés J. Bohórquez ${ }^{1}$, and Ciro A. Sánchez ${ }^{1}$ \\ 1 Temperature and Humidity Laboratory, Instituto Nacional de Metrología de Colombia - INM, Bogotá D.C 111321, Colombia \\ ${ }^{2}$ Departamento de Ingeniería Química y Ambiental, Universidad Nacional de Colombia, Bogotá 11001, Colombia
}

Received: 21 October 2019 / Accepted: 18 November 2019

\begin{abstract}
Slim fixed-point cells are an economic and suitable alternative for calibration of industrial platinum resistance thermometers, which are widely used in research and industrial applications. The most relevant disadvantage of slim cells is related with thermal effects produced by interactions between the cell and the furnace used for the realization of the fixed-points. This work presents the implementation of a two-dimensional numerical model that considers the transient heat transfer due to conduction, radiation and latent heat. The main goal was to evaluate different geometrical parameters in the design of slim fixed-point cells. Results show that thermal effects are mitigated when the annular distance between interior and exterior walls of the crucible is maximum, while the length of the cell and the thermo-well must be setup according to the temperature gradients in the furnace to avoid undesirable heat fluxes.
\end{abstract}

Keywords: Slim fixed-point / modeling / thermal effects / ITS-90

\section{Introduction}

The objective of the National Metrology Institute of Colombia (INM) is to disseminate traceable measurements to the SI. In thermometry, this is done through calibration services using the fixed-points of the ITS-90. These fixedpoints are realized through the phase change of high purity materials such as mercury, water, gallium, indium, tin, zinc, etc. In the interval between the triple point of mercury $\left(-38.8344^{\circ} \mathrm{C}\right)$ and the freezing point of zinc $\left(419.527^{\circ} \mathrm{C}\right)$, the realization of the ITS-90 requires the use of furnaces with uniformities of the order of tens of millikelvins, as well as considerable amounts of high purity metals $(\sim 1 \mathrm{~kg})$ in addition to highly-developed facilities and expert personnel. Most of the services required by industry and academy are in this interval, therefore, it is important to develop working standards to cover the traceability demands.

In order to increase the operating capacity and to obtain a better understanding of the phenomena involved in the realization of the ITS-90, the Temperature and Humidity Laboratory of the INM has decided to construct a tin slim cell $\left(231.928^{\circ} \mathrm{C}\right)$. The main difference with traditional fixed-point cells is that slim cells contain about a quarter of the typical amount of high purity metal, which implies that the realization in slim cells can be done in less demanding facilities. The consequence of the use of slim cells instead of traditional ones, is a poor thermal contact

\footnotetext{
* Corresponding author: sacarvajal@inm.gov.co
}

between the thermometer and the material undergoing the phase transition, which is evidenced as a high contributions of the thermal effects in the measurement uncertainty [1]. Due to this limitation, Standard Platinum Resistance Thermometers (SPRTs), which have the higher accuracy available are not calibrated using slim cells. However, in applications with lower accuracy requirements such as calibration of Industrial Platinum Resistance Thermometers (IPRTs) [2], calibration of thermocouples [3] or study of impurity effects [4], slim cells fit the purpose.

The thermal effects are a consequence of dynamic and static behaviors. Dynamic thermal effects are related with the heat capacity of the cell-thermometer system and its geometry, while static thermal effects are related with the heat fluxes generated between the sensing element of the thermometer and the colder and warmer zones of the cell [5]. Regarding the static thermal effects, its two main contributions are the heat transfer between the sensing element and the furnace and the heat transfer between the sensing element and the external surroundings [6]. While the effect of the external surrounding can be reduced using a proper immersion of the thermometer in the cell, the interaction between the furnace and the cell can be more complex to manage, this is especially important in slim cells designed for tin due to the influence of the supercooling behavior in freezing curves [7] and impurity distributions in melting curves [8].

In order to find the optimal geometrical parameters that allow the minimization of the aforementioned effects, a two-dimensional numerical simulation was implemented 


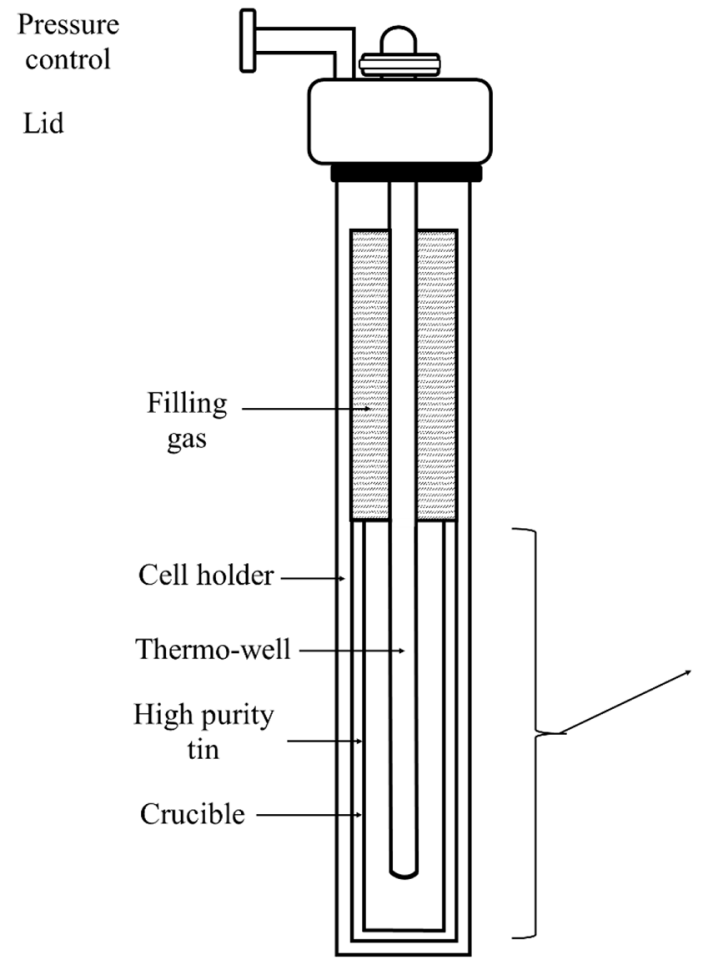

(a)

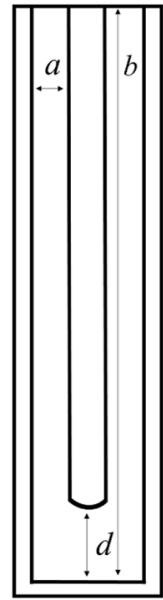

(b)

Fig. 1. Fixed-point cell scheme, (a) main components, (b) geometrical parameters of the crucible.

using the finite-element method by means of the commercial software FLUENT ${ }^{\circledR}$. The coupled effects of phase transition, heat conduction and radiation heat transfer on transient mode were evaluated in the cell assembly as well as in the thermometer, mainly considering the influence on the sensing element.

\section{Methodology}

\subsection{Geometry of the cell}

The main components and the structure of a slim fixedpoint cell are presented in Figure 1a. The cell consists of a high-purity metal contained in a crucible, which is designed to enhance the formation of a liquid-solid interface around the thermo-well, where a temperature sensor can be introduced. The crucible and the thermowell are assembled into a cell holder, which is sealed at the top, to ensure a constant pressure of $101325 \mathrm{~Pa}$ inside the cell.

Figure 1b presents the geometrical parameters used in the design of the crucible. The parameter $a$ corresponds to the annular distance between interior and exterior walls of the crucible, $b$ is the length of high purity material contained in the crucible and $d$ is the distance between the bottom of the thermo-well and the bottom of the crucible.

The fixed-point cell was modeled as a two-dimensional system with axial symmetry, as shown in Figure $2 \mathrm{~b}$ and $\mathrm{c}$. The cell was divided into two sections and eight

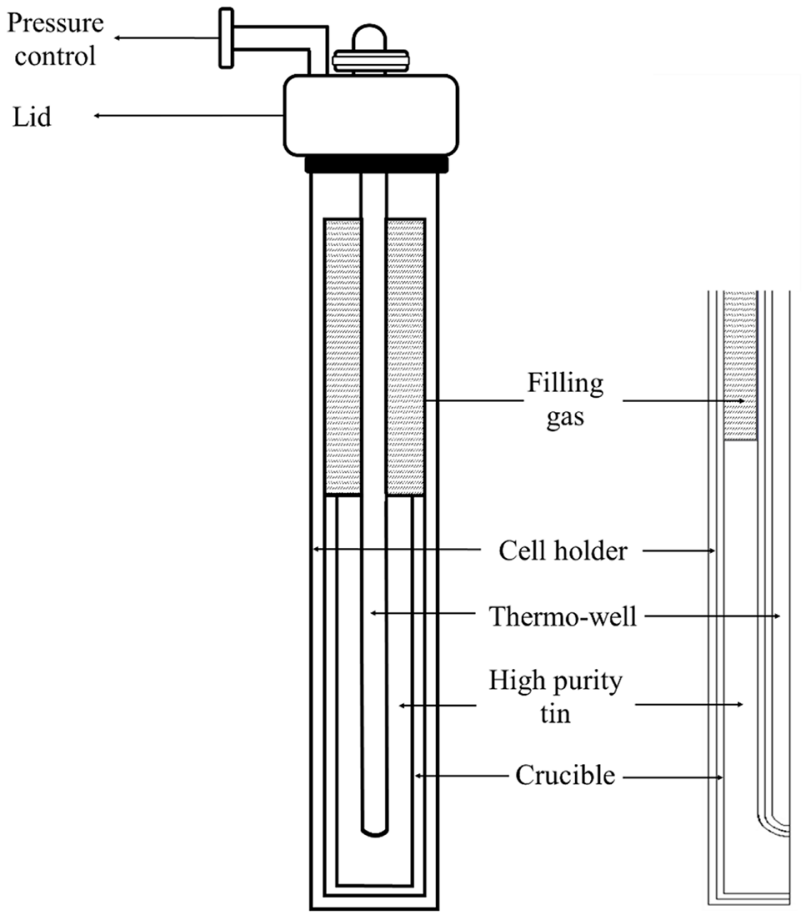

(a) (b)

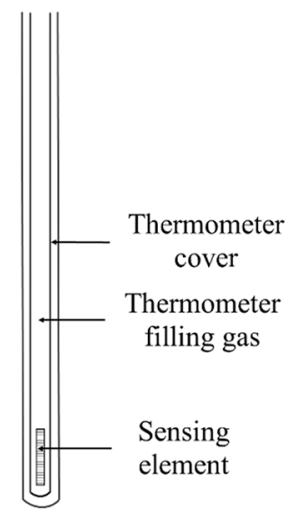

(c)

Fig. 2. Fixed-point cell assembly model, (a) main components, (b) cell model, (c) thermometer model. 
Table 1. Thermophysical properties of the materials used.

\begin{tabular}{llllll}
\hline Material & $\begin{array}{l}\text { Density } \\
\mathrm{kg} / \mathrm{m}^{3}\end{array}$ & $\begin{array}{l}\text { Thermal } \\
\text { conductivity } \\
\mathrm{W} / \mathrm{m}-\mathrm{K}\end{array}$ & $\begin{array}{l}\text { Heat capacity } \\
\mathrm{J} / \mathrm{K}-\mathrm{kg}\end{array}$ & Emissivity & $\begin{array}{l}\text { Latent heat } \\
\mathrm{J} / \mathrm{kg}\end{array}$ \\
\hline Tin - Solid & $7400[9]$ & $54.2[10]$ & $258.7[9]$ & - & 59221.5 \\
Tin - Liquid & $6992[9]$ & $29.3[10]$ & $240.1[9]$ & - & - \\
\hline Graphite & $2260[11]$ & $600[12]$ & $1229.4[13]$ & $0.9[11]$ & - \\
Stainless Steel - 303 & $8000[14]$ & $18.0[14]^{*}$ & $500[14]$ & $0.745[15]$ & - \\
Platinum & $21450[16]$ & $72.3[10]$ & $138.6[17]$ & - & - \\
Inconel & $8420[18]$ & $18.8[10]$ & $460[18]$ & - & - \\
\hline
\end{tabular}

*Linearly interpolated.

sub-domains distributed as follows:

Section 1: Cell (Fig. 2b)

- Filling gas

- Cell holder

- Thermo-well

- High purity tin

- Crucible

Section 2: Thermometer (Fig. 2c)

- Thermometer cover

- Thermometer filling gas

- Sensing element

\subsection{Materials properties}

The crucible material was simulated as high-purity graphite, the filling gas as high-purity argon and the thermo-well and the cell holder as stainless steel 303 . The thermometer was modeled as a platinum wire inside a hollow Inconel sheathing containing argon as filling gas. The thermophysical properties of the materials used are presented in Table 1, potential impurities were not considered.

\subsection{Numerical model}

The transient energy balance over the measurement system can be written as:

$$
\frac{\partial}{\partial t}(\rho H)=\nabla \cdot(k \nabla T)-\nabla \cdot q_{R}
$$

where $\rho$ is the density, $H$ is the enthalpy, $k$ is the thermal conductivity, $T$ is the temperature and $q_{R}$ is the radiative heat flux. The enthalpy in equation (1) can be expressed as:

$$
H=h+\Delta H
$$

where the term $h$ represents the contribution due to the sensible heat and $\Delta H$ represents the contribution due to the latent heat. The last one is associated with the high-purity metal and was computed through the enthalpy-porosity technique proposed by Brent et al. [19]. This technique is especially useful for solving diffusion phase-change problems through fixed-grid methods. The cells of the fixed-grid in the region undergoing the phase transition are numerically modeled as a pseudo porous media, where the porosity is equal to zero in the solid phase and equal to unity in the liquid phase. The porosity $\beta$ relates $\Delta H$ to the latent heat of the material $L$ through equation (3), and can be expressed as a linear function of temperature, according to equation (4):

$$
\begin{gathered}
\Delta H=\beta L \\
\left\{\begin{array}{l}
\beta=0 \rightarrow T<T_{s} \\
\beta=1 \rightarrow T>T_{l} \\
\beta=\frac{T-T_{s}}{T_{l}-T_{s}} \rightarrow T_{s}<T<T_{l}
\end{array}\right.
\end{gathered}
$$

where $T_{s}$ is the temperature when all the material is solid and $T_{l}$ is the temperature when all the material is molten.

The radiative heat transfer was estimated through the diffuse-gray approximation and assuming non-participating media. In this case, the radiative component can be calculated with equation (5).

$$
q_{R}=\frac{\varepsilon}{1-\varepsilon}\left(\sigma T^{4}-J\right)
$$

where $\varepsilon$ is the emissivity, $\sigma$ is the Steffan-Boltzman constant and $J$ is the total heat flux leaving the surface, often called radiosity. The radiosity is calculated from the view factor $F$ at each surface $i$, according to equation (6) [20].

$$
J_{i}=\varepsilon \sigma T^{4}+(1-\varepsilon) \sum_{j=1}^{N} J_{j} F_{i-j}
$$

\subsection{Thermal effects}

Ideally, in the realization of a fixed-point, the sensing element of the thermometer is completely surrounded by the liquid-solid interface, as shown in Figure 3a. Due to the heat transfer between cell, furnace and environment, the 


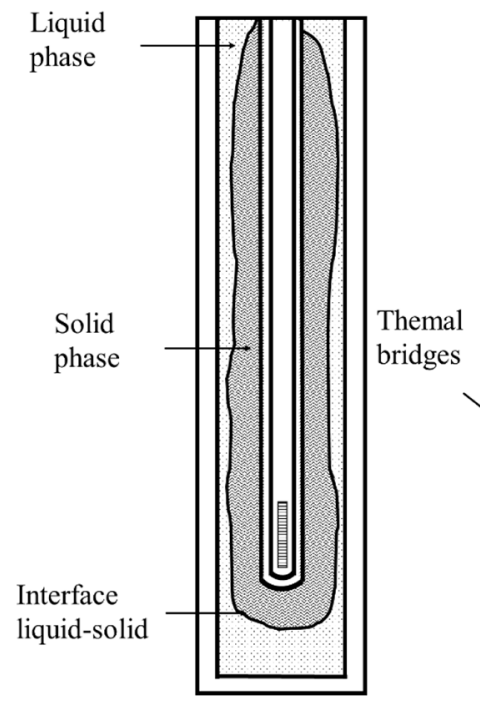

(a)

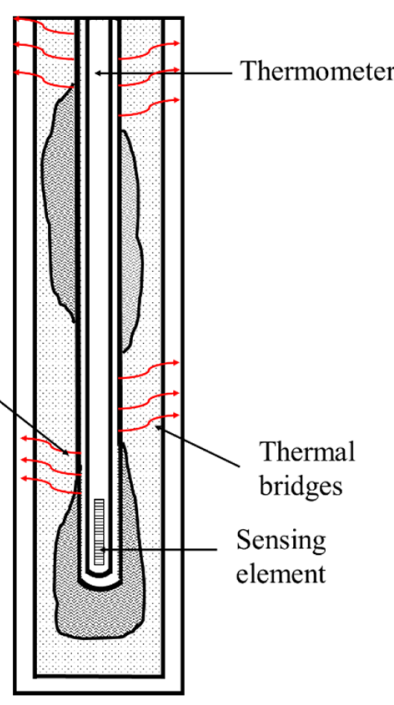

(b)
Fig. 3. Representation of thermal effects in a fixed-point cell. (a) Proper liquid-solid interface. (b) Discontinuous liquid-solid interface.

interface can be moved from the ideal position or even disappear in some regions, promoting the development of thermal bridges between the sensing element and the furnace, as shown in Figure 3b. These phenomena are known as "thermal effects" and along with impurities, they represent the major contributions to the uncertainty when realizing the fixed-points [21].

In order to evaluate the influence of thermal effects on different geometrical configurations of the crucible, the penetration ratio $\mu$ was calculated using the methodology suggested by Fahr and Rudtsch [6] through equation (7):

$$
\mu=\frac{\Delta T_{\text {meas }}}{\Delta T_{i}}
$$

where $\Delta T_{\text {meas }}$ is the change in temperature measured in the cell due to the change in the furnace temperature $\Delta T_{i}$. If the parameter $\mu$ is equal to 0 , then there is a proper fixed-point realization, i.e. a total absence of thermal effects. If $\mu$ is equal to 1 , it means the worst possible realization, where the effect of the wall temperature dominates the measurement. The penetration ratio as a function of time is presented in Figure 4, where the red curve is the profile assigned to the furnace temperature and the blue curve is the temperature measured in the cell.

\subsection{Boundary conditions}

The boundary conditions were imposed on the cell holder and on the lid, as depicted in Figure 5. In order to calculate the penetration ratio $\mu$, the wall temperature on the cell holder was established as a time-dependent rectangular function, as shown in Figure 4 (red curve) varying the temperatures between $504.778 \mathrm{~K}$ and $504.978 \mathrm{~K}$. On the lid of the cell a convective boundary condition was imposed.

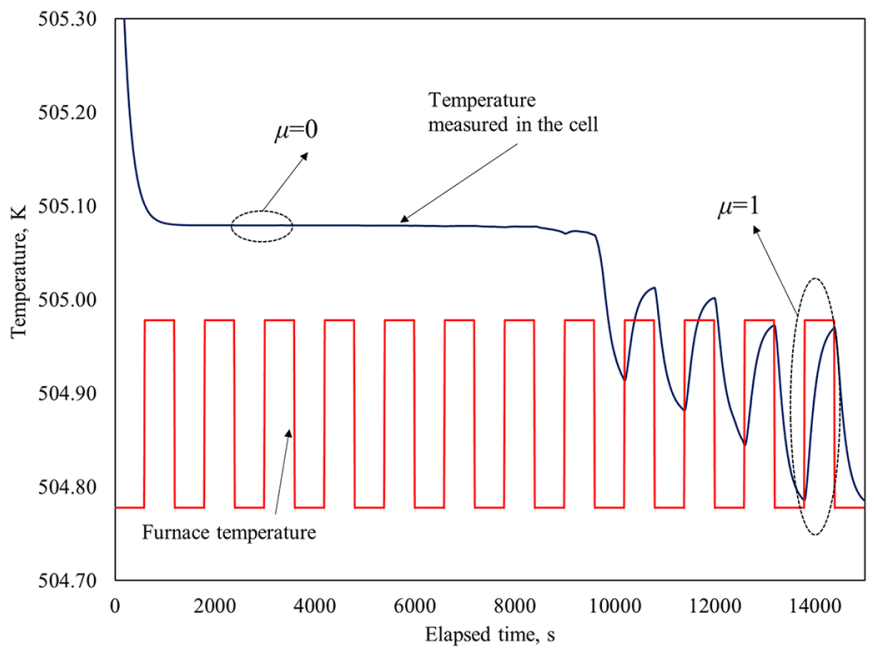

Fig. 4. Penetration ratio $\mu$ in a fixed-point realization. Cell temperature (blue) and furnace temperature of the cell (red). $\alpha=8 \mathrm{~W} / \mathrm{m}^{2} \cdot \mathrm{K}$

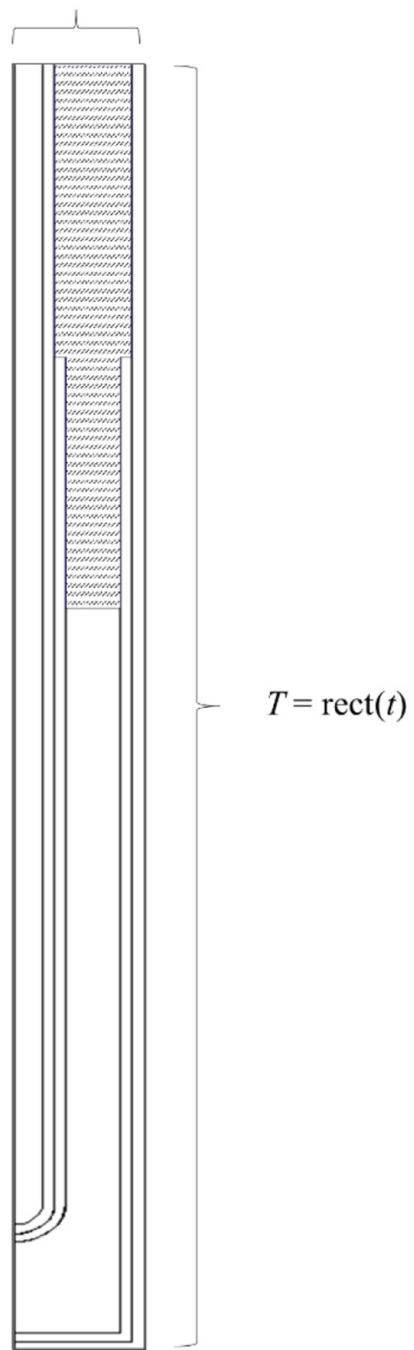

Fig. 5. Fixed point cell boundary conditions. 


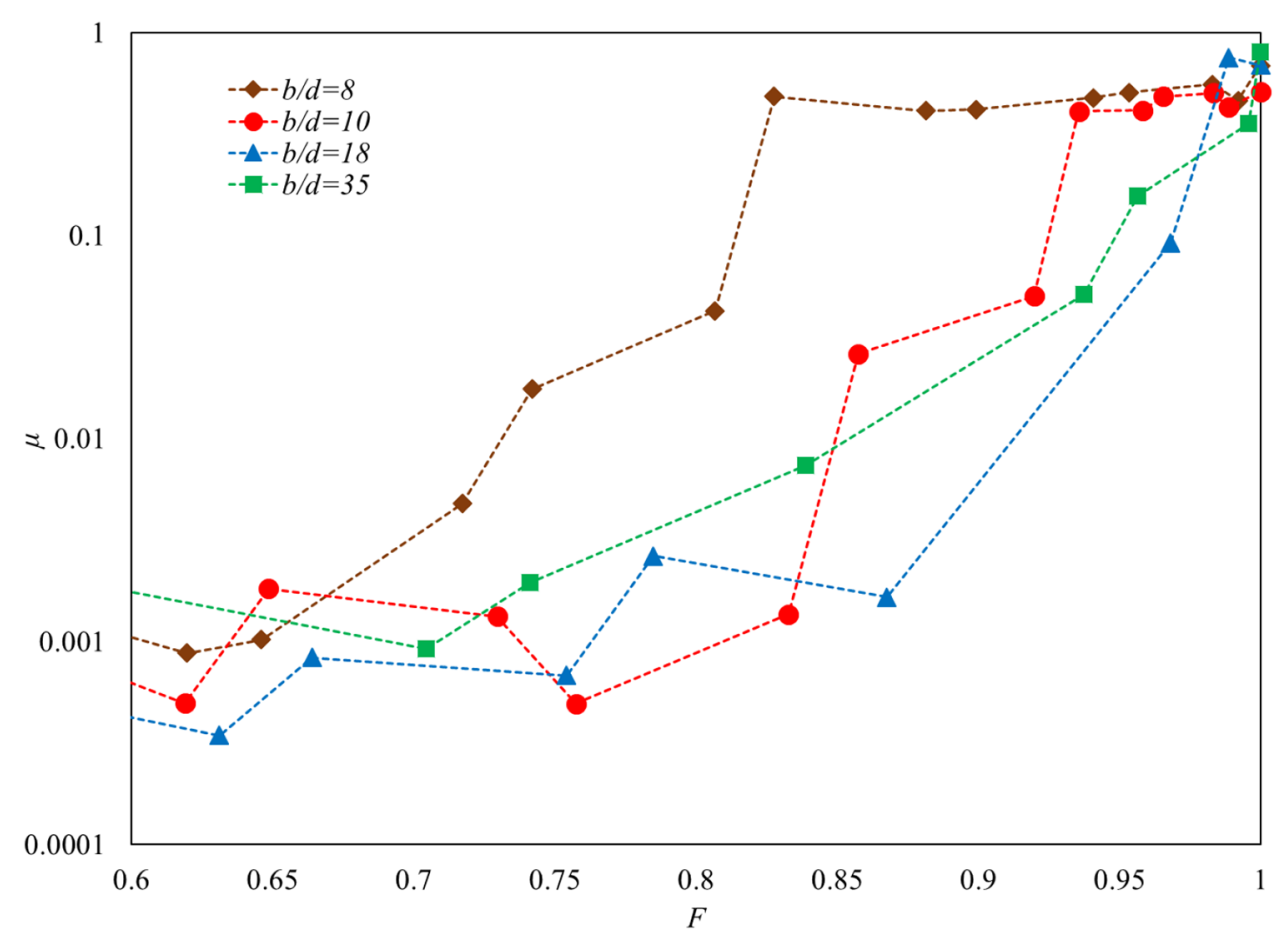

Fig. 6. Penetration ratio $\mu$ as a function of the solid fraction $F$ for different $b / d$ ratios at $a$ constant.

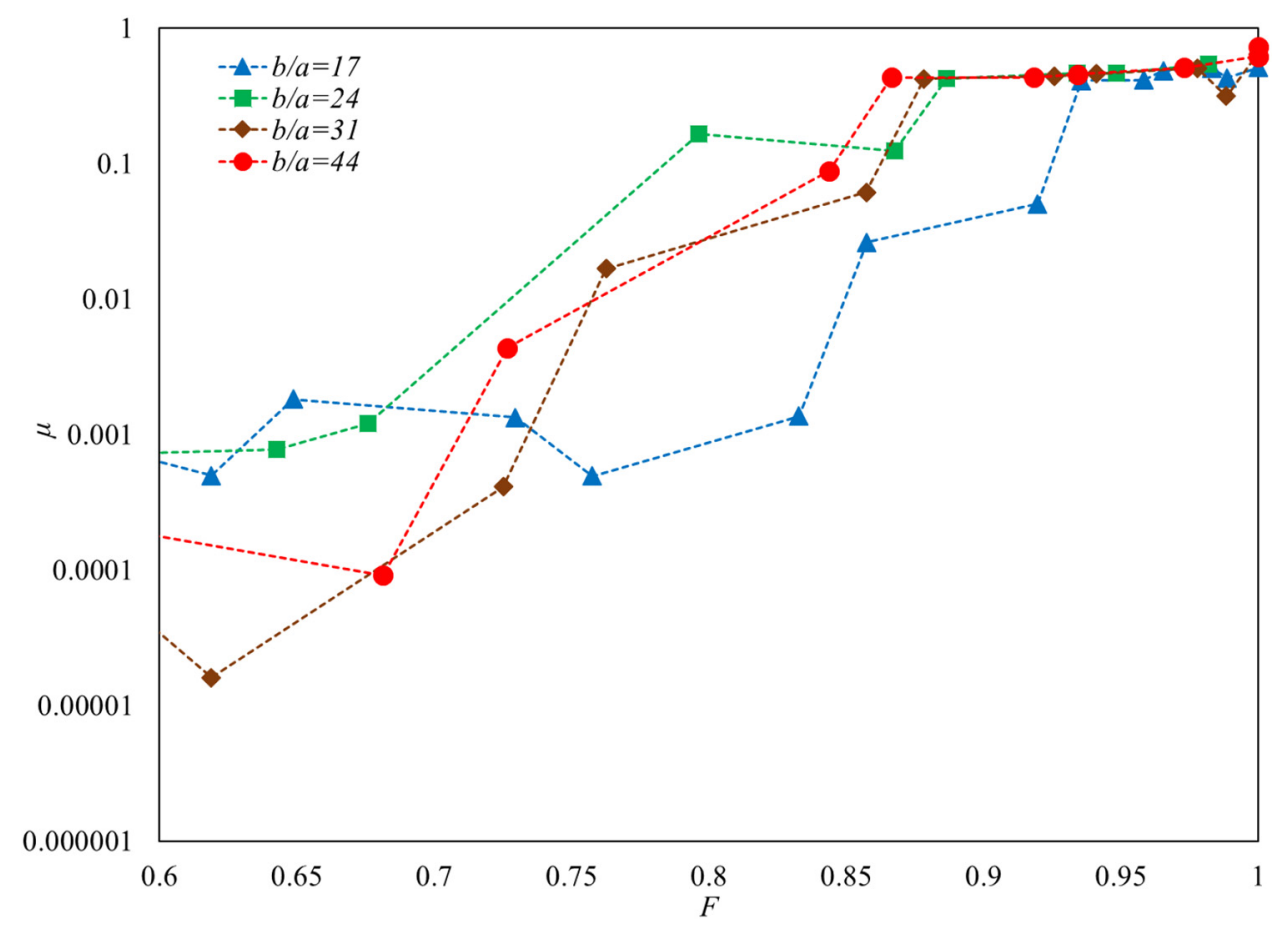

Fig. 7. Penetration ratio $\mu$ as a function of the solid fraction $F$ for different $b / a$ ratios at $d$ constant.

For different configuration of the parameters $a, b$ and $d$ of Figure 1, the coupled equations (1)-(6) were solved using the finite-element method implemented in the software FLUENT $^{\circledR}$ with the boundary conditions defined in Figure 5.

\section{Results and discussion}

Figures 6-8 present the penetration ratio for different geometrical configurations for solid fraction $F$ between 0.6 and 1 . The different combinations of parameters $a, b$ and $d$ 


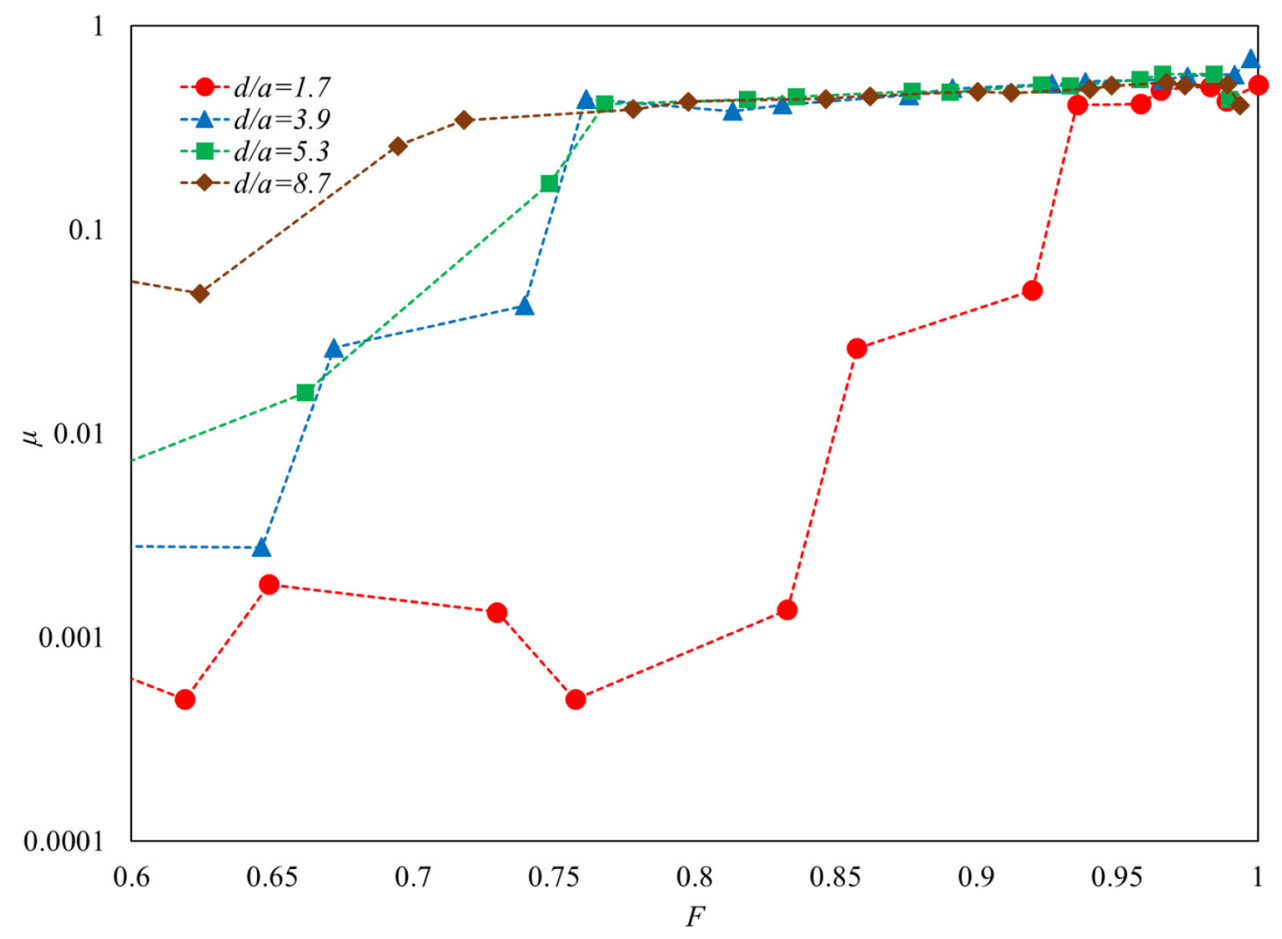

Fig. 8. Penetration ratio $\mu$ against solid fraction $F$ for different $d / a$ ratios at $b$ constant.

have the restriction of producing the same amount of highpurity metal inside the crucible in order for the results to be comparable. As pointed out by Krizmanic et al. [22] the coupled calculations of conductive and radiative heat transfer implemented in FLUENT $^{\circledR}$ can produce errors in the order of $0.1 \mathrm{mK}$ in the relative position of the plateau, however, the results of the simulation are useful in analyzing tendencies. It is also important to note that the model represents only the macroscopic effects and it did not consider microscopic effects related with crystal growth and nucleation, which are important in the analysis of initiation techniques [23].

Figure 6 shows the variation of the penetration ratio with the solid fraction at different $b / d$ ratios, keeping $a$ constant. All the penetration ratios present an increasing trend at $b / d=8$ and $b / d=10$, forming a flat region from $F=0.82$ and $F=0.95$, respectively. At $b / d=8$, the penetration ratio is larger with respect to the other $b / d$ ratios from $F=0.7$. At $b / d=10$, the penetration ratio is larger than $b / d$ ratios between 18 and 35 from $F=0.85$. The flat regions indicate that thermal effects dominate the process, therefore it can be concluded that thermal effects begin to be significant at lower $F$ values when the $b / d$ ratio decreases between 8 and 10, however, between 18 and $35 \mathrm{~b} /$ $d$ ratios, the thermal effects are slightly larger for the highest $b / d$ ratio. This indicates that there is an optimal $b /$ $d$ ratio that minimizes the penetration ratio. The marked effect of the $b / d$ ratio on the realization of the fixed-point is related to the heat flux through the sensing element of the thermometer. In short cells with excessive volume of highpurity metal below the bottom of the thermo-well and a small volume in the surrounding area of the thermometer, i.e. low $b / d$ ratios, the liquid-solid interface along the thermometer is not enough to guarantee a uniform temperature distribution in the sensing element.

Figure 9 illustrates the temperature profiles across the sensing element of the thermometer in the fixed-point assembly for the $b / d$ ratios of Figure 6 with solid fractions of $0.6,0.8$ and 0.95 . At $F=0.6$, there are no temperature gradients around the sensing element, indicating that thermal effects from the furnace are low. When $F=0.8$, there is a displacement of the isothermal zone around the sensing element. At lower $b / d$ ratios, the liquid-solid interface goes to the bottom of the crucible, uncovering the tip of the sensing element, which increases the thermal effects. At the end of the plateau, using an $F=0.95$, the previous pattern is more evident. At $b / d=8$ and $b / d=10$, the sensing element is far from the isothermal zone, while at $b / d=35$, the liquid-solid interface moves to the top of the sensing element uncovering the tip. At $b / d=18$ and $F=0.95$, the isothermal zone is smaller than $b / d=35$, but the liquid-solid interface is better distributed around the sensing element, which explains the behavior of the penetration ratio when $F$ is close to 1 . It is important to note that, at $b / d=35$ and $F=0.95$, a higher temperature on the bottom of the furnace will produce an isothermal zone more uniform around the sensing element. As pointed out by Pearce et al. [24] there is an optimum temperature distribution in the axial direction of the furnace that minimizes thermal effects, which means that the appropriate $b / d$ ratio will depend on the vertical profile of the furnace.

Figure 7 shows the variation of the penetration ratio with the solid fraction at different $b / a$ ratios, keeping $d$ constant. As indicated by the presence of flat regions, thermal effects become dominant at lower $F$ values when 

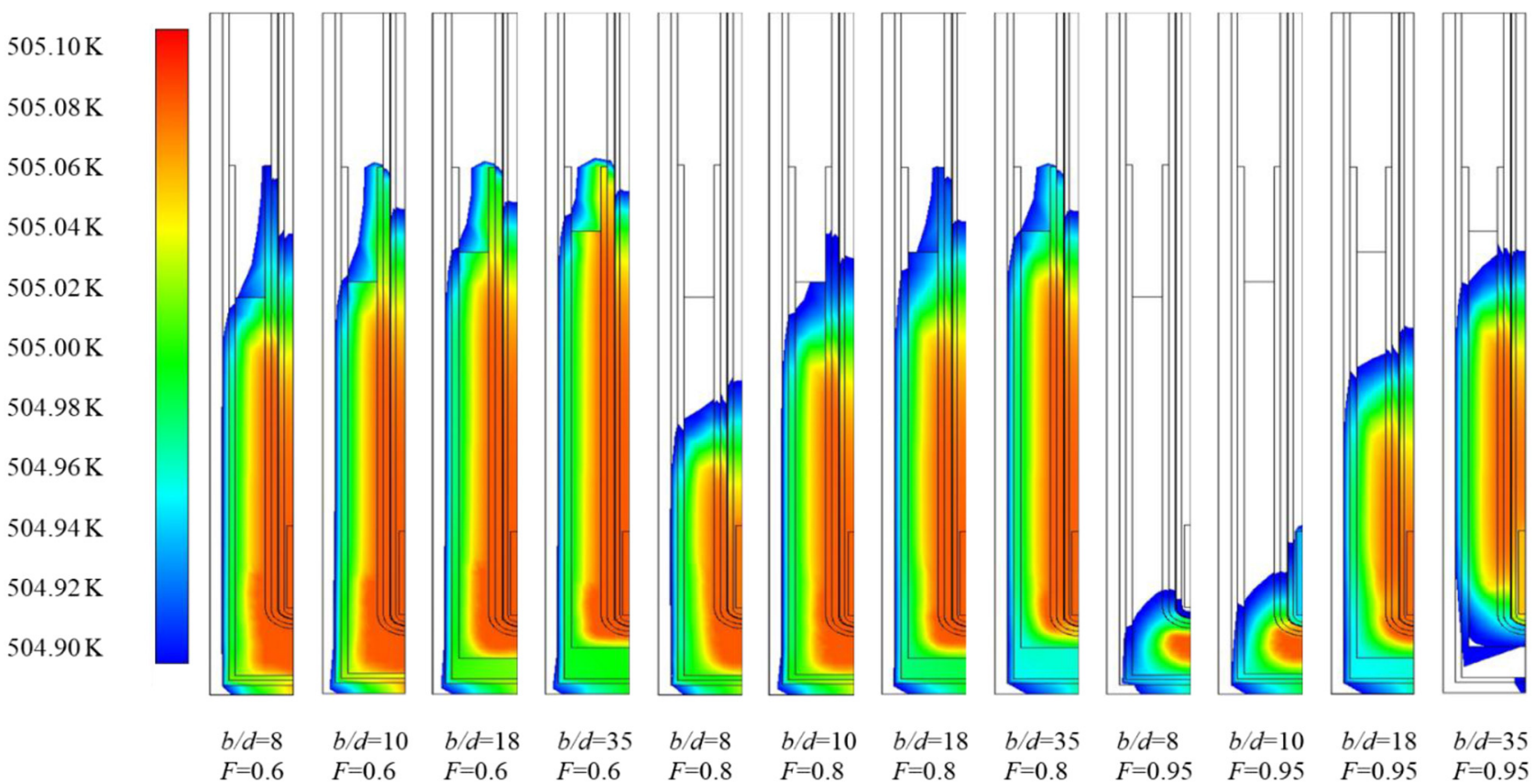

Fig. 9. Temperature profiles of different $b / d$ ratios for solid fraction $F$ between 0.6 and 1 (white sections represent temperatures lower than $504.9 \mathrm{~K})$.

the $b / a$ ratio increases, for instance, at $b / a=17$ the flat region begins at $F=0.94$ while at $b / a=44$ the flat region begins at $F=0.86$. It also shows that even at high $b$ values, the effect of the annular distance $a$ is relevant for a proper realization of the fixed-point, since at low annular distances there is not enough space for the formation of a uniform phase boundary, which in turn promotes the development of thermal bridges between the furnace and the sensing element of the thermometer, as mentioned by Fahr et al. $[5]$.

Figure 8 shows the variation of the penetration ratio as a function of the solid fraction at different $d / a$ ratios, keeping $b$ constant. Once again, low annular distances impair the formation of a uniform phase boundary as explained previously. At $d / a=8.7$, the thermal effects dominate the realization even for a solid fraction as low as 0.6. Consequently, at lower values of the $d / a$ ratio, the thermal effects become less important, as shown at $d / a=1.7$.

As observed in Figures 6-8, especially with an $F>0.8$, lower penetration ratios, i.e. lower thermal effects, are obtained at higher $b / d$ ratios and at lower $b / a$ and $d / a$ ratios; this means that the design of slim cells should have the maximum $a$ distance, keeping a $b / d$ ratio high enough to assure a uniform liquid-solid interface near to the sensing element of the thermometer, considering the vertical temperature profile of the furnace.

\section{Conclusions}

The modeling of thermal effects due to furnace-cell interaction in a slim cell was used to evaluate different geometrical designs for the realization of the freezing point of tin. The fixed-point cell assembly was modeled as a twodimensional axisymmetric system that considers transient conductive-radiative heat transfer and the latent heat released during the freezing process through the diffusegray approximation and the enthalpy-porosity method, respectively. The evaluation of thermal effects was done through the penetration ratio, which relates the variation in the temperature of the furnace to the temperature measured in the cell.

The results indicate that the geometrical parameters of the crucible can be optimized in order to minimize the penetration ratio and consequently reduce thermal effects. It was found that the annular distance between interior and exterior walls of the crucible should be as long as it can be in order to guarantee the proper formation of a phase boundary that avoids generation of thermal bridges between the furnace and the sensing element of the thermometer. The length of the cell and the thermo-well should be established in accordance with the vertical temperature profile of the furnace, since the form and location of the liquid-solid interface depends on the thermal profile developed inside the cell.

\section{References}

1. G.F. Strouse, Small fixed-point cells for use in dry well block calibrators, in Proceedings of TEMPMEKO, 2001, pp. $783-788$

2. X. Li, D. Farley, D. Chen, M. Zhao, M. Hirst, Mini metalcased fixed-point cells, in Proceedings of 8th International 
Symposium on Temperature and Thermal Measurements in Industry and Science, 2001, 2, pp. 777-782

3. F. Edler, S. Haupt, S.-A. Mokdad, G. Failleau, M. Sadli, Investigation of self-validating thermocouples with integrated fixed-point units, Int. J. Metrol. Qual. Eng. 6, 103 (2015)

4. M. Fahr, S. Rudtsch, Oxides in metal fixed points of the ITS90, Metrologia 46, 423-438 (2009)

5. M. Fahr, S. Rudtsch, A.-K. Gerlitzke, Fixed-point comparison uncertainties for two cell geometries, Int. J. Thermophys. 32, 2269-2280 (2011)

6. M. Fahr, S. Rudtsch, A new method for the quantification and correction of thermal effects on the realization of fixed points, Int. J. Thermophys. 29, 126-138 (2008)

7. M. Ragay-Enot, Y.H. Lee, Y.-G. Kim, Fabrication of a mini multi-fixed-point cell for the calibration of industrial platinum resistance thermometers, Meas. Sci. Technol. 28, 075007 (2017)

8. E.V. Vasil'ev, A.A. Ignatov, M.I. Kalinin, L.D. Markin, Investigation of the reproducibility of melting and freezing curves for tin in a miniature cell, Meas. Tech. 61, 494-500 (2018)

9. G.G. Graf, Tin, Tin alloys, and Tin Compounds, Ullmann's encyclopedia of industrial chemistry (Wiley-VCH Verlag GmbH \& Co. KGaA, Weinheim, 2012)

10. Y.S. Touloukian, R.W. Powell, C.Y. Ho, P.G. Klemens, Thermal conductivity: metallic elements and alloys (IFI/ Plenum, New York, NY, 1970)

11. H.O. Pierson, Handbook of carbon, graphite, diamonds and fullerenes: processing, properties and applications (Noyes Publications, New Jersey, 1993)

12. R. Taylor, The thermal conductivity of pyrolytic graphite, Philos. Mag. 13, 157-166 (1966)
13. A.T.D. Butland, R.J. Maddison, The specific heat of graphite: an evaluation of measurements, J. Nucl. Mater. 49, 45-56 (1973)

14. P.D. Harvey, Engineering properties of steel (American Society for Metals, Ohio, 1982)

15. Y.S. Touloukian, D.P. DeWitt, Thermal radiative properties: metallic elements and alloys (Springer, New York, 1970)

16. H. Renner et al., Platinum group metals and compounds, Ullmann's encyclopedia of industrial chemistry (Wiley-VCH GmbH, Weinheim, 2000)

17. H. Yokokawa, Y. Takahashi, Laser-flash calorimetry II. Heat capacity of platinum from 80 to $1000 \mathrm{~K}$ and its revised thermodynamic functions, J. Chem. Thermodyn. 11, 411-420 (1979)

18. W.F. Gale, T.C. Totemeier, Smithells metals reference book (Elsevier Science, Amsterdam, 2003)

19. A.D. Brent, V.R. Voller, K.T.J. Reid, Enthalpy-porosity technique for modeling convection-diffusion phase change: Application to the melting of a pure metal, Numer. Heat Transf. Part A Appl. 13, 297-318 (1988)

20. M.F. Modest, Radiative heat transfer (Elsevier Science, Amsterdam, 2013)

21. J.V. Pearce et al., Guide to the Realization of the ITS-90 Metal Fixed Points for Contact Thermometry, BIPM, 2018

22. S. Krizmanic, T. Veliki, D. Zvizdic, Modeling of transient heat transfer in zinc fixed-point cell, Int. J. Thermophys. 32, 326-336 (2011)

23. D.R. White, R.S. Mason, Improved initiation technique for the metal fixed points, Int. J. Thermophys. 32, 348-359 (2011)

24. J.V. Pearce, R.I. Veltcheva, D.H. Lowe, Z. Malik, J.D. Hunt, Optimization of SPRT measurements of freezing in a zinc fixed-point cell, Metrologia 49, 359 (2012)

Cite this article as: Sergio A. Carvajal, J. Herney Ramírez, Andrés J. Bohórquez, Ciro A. Sánchez, Modelling of thermal effects in a slim tin fixed-point cell, Int. J. Metrol. Qual. Eng. 10, 17 (2019) 